\title{
MESH-TO-BIM: FROM SEGMENTED MESH ELEMENTS TO BIM MODEL WITH LIMITED PARAMETERS
}

\author{
X. Yang*, M. Koehl, P. Grussenmeyer \\ Photogrammetry and Geomatics Group, ICube Laboratory UMR 7357, INSA Strasbourg, France \\ (xiucheng.yang, mathieu.koehl, pierre.grussenmeyer)@insa-strasbourg.fr
}

Commission II/WG8

KEY WORDS: Architectural Heritage, BIM, Documentation, Ruins, Segmented elements, Visual programming

\begin{abstract}
:
Building Information Modelling (BIM) technique has been widely utilized in heritage documentation and comes to a general term Historical/Heritage BIM (HBIM). The current HBIM project mostly employs the scan-to-BIM process to manually create the geometric model from the point cloud. This paper explains how it is possible to shape from the mesh geometry with reduced human involvement during the modelling process. Aiming at unbuilt heritage, two case studies are handled in this study, including a ruined Roman stone architectural and a severely damaged abbey. The pipeline consists of solid element modelling based on documentation data using Autodesk Revit, a common BIM platform, and the successive modelling from these geometric primitives using Autodesk Dynamo, a visual programming built-in plugin tool in Revit. The BIM-based reconstruction enriches the classic visual model from computer graphics approaches with measurement, semantic and additional information. Dynamo is used to develop a semi-automated function to reduce the manual process, which builds the final BIM model from segmented parametric elements directly. The level of detail (LoD) of the final models is dramatically relevant with the manual involvement in the element creation. The proposed outline also presents two potential issues in the ongoing work: combining the ontology semantics with the parametric BIM model, and introducing the proposed pipeline into the as-built HBIM process.
\end{abstract}

\section{INTRODUCTION}

Building Information Modelling (BIM), as an initial instrument for the parametric design of new buildings, shows potentialities for applications to the documentation of architectural heritage. The general term, Historical/Heritage BIM (HBIM) (Murphy et al., 2009), is mostly the as-built HBIM process finished by the well-known scan-to-BIM process (Volk et al., 2014). The point cloud is imported into the BIM software, and the solid building components can be created by existing BIM IFC classes and selfdefined structures.

The priority of architectural heritage compared to general buildings lies in the possible access to documentation materials. Current HBIM projects combine the existing documentation and reality-based point clouds (Fai and Rafeiro, 2014; Murphy et al., 2013; Barazzetti et al., 2015; Biagini et al., 2016). A library of BIM parametric architectural elements is first created according to the historical manuscripts. And reverse engineering technique is then utilized to map the solid components into point cloud.

However, built heritage suffers from human made damage and natural disaster. When a particular building no longer exists, the point cloud may be not available. The accessible data source is limited to the archived materials (such as historical documents, bibliographic references, photographs, drawings, etc.) and remaining damaged sites (ruins and partly existing structures). The current virtual reconstruction to unveil the existence of the ruined and damaged historic buildings is mostly conducted by shape-grammar of computer graphics technique (Quattrini and Baleani, 2015; Dylla et al., 2008). BIM goes further than computer graphics to improve the virtual reconstruction of an information-rich model with parametric and semantic elements
(Yang et al., 2016). The model is not only a virtual representation of the construction but also becomes information objects with parametric intelligence (De Luca et al., 2011).

BIM technique shows dramatic propriety in information richness and management, but its modelling process is mostly conducted in time-consuming manual ways. Currently, many commercial tools (ClearEdge3D Edgewise, IMAGINit Scan to BIM, Pointsense and Leica CloudWorx) and self-developed algorithms (Xiong et al., 2013; Thomson and Boehm, 2015; Macher et al., 2017) are dedicated to reducing the human involvement during the scan-to-BIM process. As for the ruined heritage, unbuilt HBIM concept, utilized to re-create the past/disappeared heritage according to the documentation, pays little attention to automated modelling.

Recent works using BIM technique on demolished historic buildings focused on the comparison of semantic HBIM model with traditional CAD modelling systematics (Boeykens et al., 2012; Apollonio et al., 2013; Ludwig et al., 2013). And such processing is conducted entirely by manual processing, which is accordant with the original BIM bottom-up process: parametric modelling of the specific parts for the studied heritage, and then integrating the elements into the BIM model (Casu and Pisu, 2016). Anyway, it is expected to generate BIM models using an automatic/semi-automatic method (López et al., 2017).

As far as our knowledge, there are few works to reduce the human involvement during the BIM modelling process from existing geometric primitives. This research focuses on the $3 \mathrm{D}$ parametric modelling of lost architectural heritage from the archived documentation and ruins (Fig. 1).

* Corresponding author 


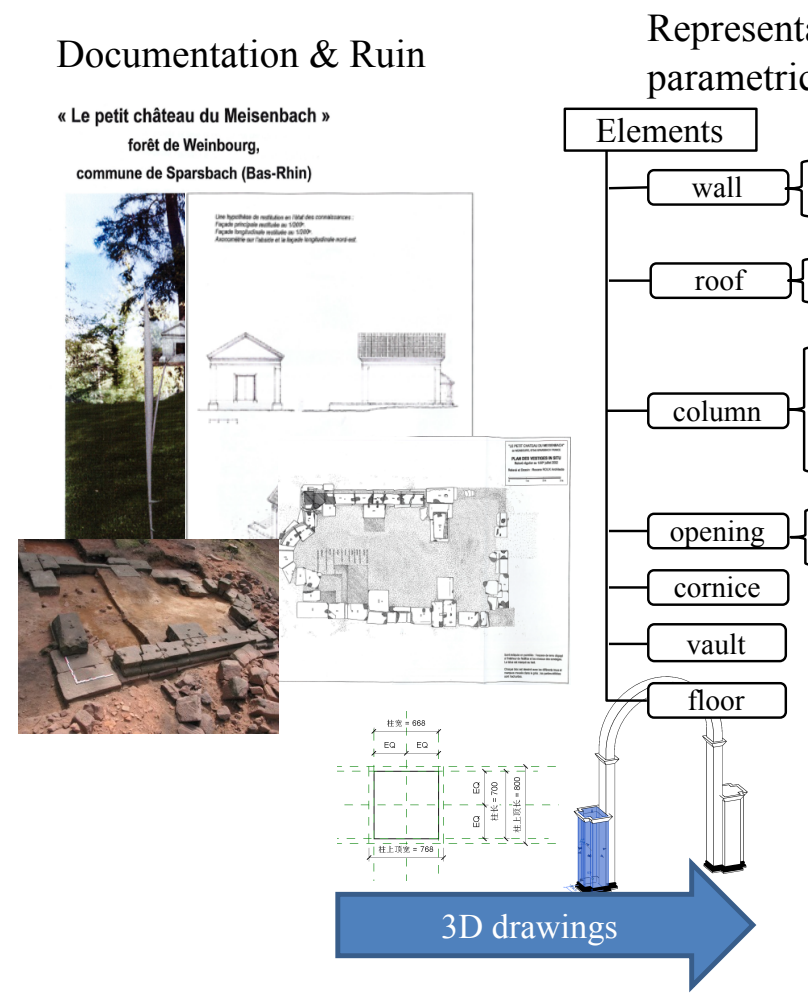

BIM platform

Semantic model

Fig. 1. Workflow from documentation recording to parametric elements and BIM model
The primary goals presented in this paper were essential of two aspects. The first is an applicative one, aiming to develop a parametric model for unbuilt historic buildings on use of building information modelling technique; the second is a methodological one, towards the automation of the modelling from solid elements and reduction of human involvement rather than manual building information modelling process.

The proposed approach has been implemented onto two unbuilt historic buildings (Section 2.1) through the practical BIM tool, Autodesk Revit platform and Dynamo visual programming plugin. The BIM parametric elements (i.e., columns, roof, slabs, and walls) (Section 2.2) are manually created according to the historical archive of the dimensional shape and the scanning of remaining structures, and then a semi-automatic modelling procedure is developed by Dynamo visual programming to build the geometric primitives to the semantic BIM model (Section 2.3). Section 3 presents the final BIM model in moderate level of detail (LoD) and discusses the expecting improvement and potential application of the proposed pipeline. The conclusion is drawn in Section 4

\section{MATERIALS AND METHODS}

\subsection{Employed ruined historic buildings}

This project utilises BIM technique to re-create two destroyed historic buildings in Alsace, France, an antique monument named Petit château du Meisenbach and a church of the Abbey of Niedermunster. The first monument is a ruined old castle constructed of stones dating back to Roman times, and the various excavations which took place allow the discovery of a large number of Roman remains (Diethrich, 2017). On the spot, a paved section indicates its location and no walls exist (Fig. 2(a)). But its composing stones are distributed all around the site (Fig. 2(b)). The second church (Fig. 2(c, d)) is built between 1150 and $1180 \mathrm{AD}$, the roman style Abbey was devastated during the War of the Peasants (1525) and by two fires, in 1542 and 1572 (Koehl and Grussenmeyer, 2008). Fig. 2(c) is an aerial view of the church, and fig. 2(d) shows the existing parts. These sites would not remain much more than old stones without works of passionate archaeologist there.

The first step concerns the collection of historical data, including the bibliographic knowledge and the reality-based data of ruins. The documentation records the prototype of the building, including the compositing structure by different shapes of structures. And the geometric model has been obtained in the former works using Autodesk Inventor (Diethrich, 2017) and SketchUp (Koehl and Grussenmeyer, 2008), respectively. Then data are analysed and organised for feeding into the BIM environment according to the following BIM modelling process.

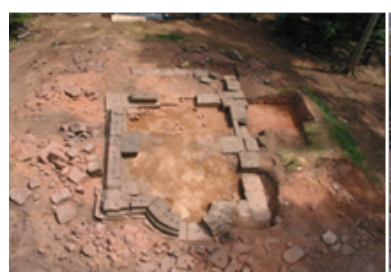

(a) site of the Petit château du Meisenbach

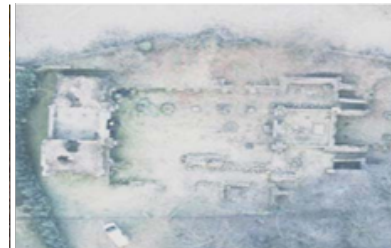

(c) site of the Abbey of Niedermunster

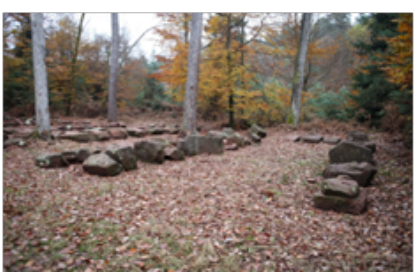

(b) existing blocks composing the monument

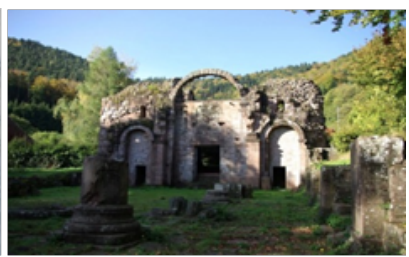

(d) existing broken parts
Fig. 2. The site of the ruins and existing broken structures 


\subsection{Parametric elements from the description books}

HBIM consists of a detailed semantic model and a library of parametric components. The library of parametric element classes (defined as "Family" in Revit) needs to be built to define the basic elements of the historic architecture. The "Family" consists of a set of rules and properties to control the parameters by which element instances can be generated (López et al., 2017). A "Family" is a group of elements with a standard set of parameters and similar graphic representation.

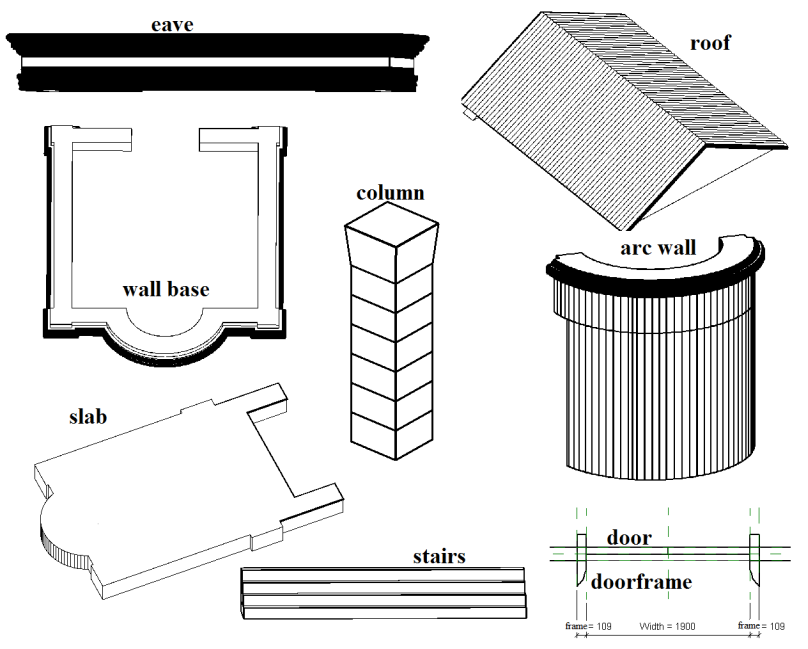

(a) "Families" for "Petit château du Meisenbach"
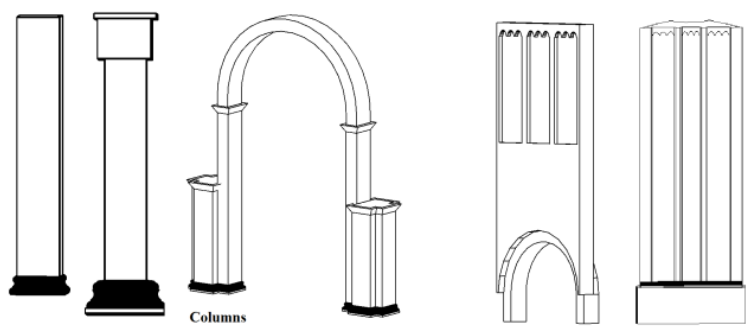

Walls
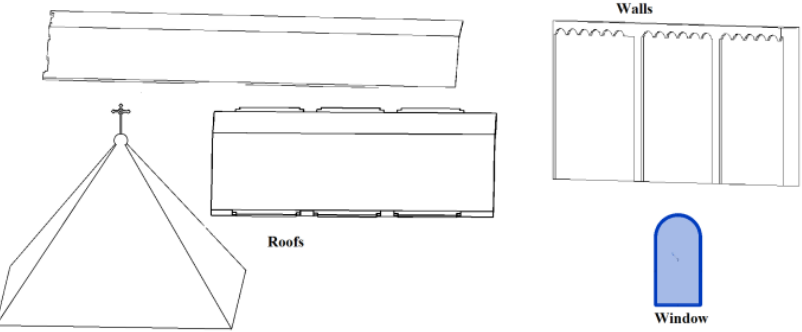

(b) "Families" for the Abbey of Niedermunster

Fig. 3. The parametric primitives created as Revit "Families"
In the project, Autodesk Revit is utilised as the BIM tool and platform for the modelling process. The modelling of the various architectural heritage objects was done in two kinds of "Families" in Revit platform (Fig. 3): "in-place family", directly built-in "Mode-In-Place" editor of "architectural" project environment, is used for the creation of realistic walls; and external component "Family", separately built in Revit Family editor, is used for the creation of other parts, such as, columns, roofs and other structures. The "in-place family" is grouped and converted into the loadable component "Family" outside the project, which can be a "wall host" family for openings and loadable family to other projects.

\subsection{Modelling from geometric primitives}

On the base of "Family" creation, the building modelling process is conducted by Autodesk Dynamo. Dynamo, an open source visual programming application, has become a built-in plugin to Revit based on Revit Application Programming Interface (API). It can interact with Revit to extend its parametric capabilities to the Revit project level and provides an environment to create customized packages using CPython and its self-defined scripting and sharing it with other users (Asl et al., 2015; Yang et al., 2017). As for the HBIM related application, Dynamo can provide following advantages: (i) possible to manipulate the Revit elements by programming, which benefits for block processing and reduce manual processing; (ii) powerful option for creating graphical representations of complex geometries (iii) supportive of mesh geometry, which can directly import the mesh geometry into Revit and create the corresponding Revit Family; (iv) potential of connection with ontology knowledge, which currently connects the Revit geometry model and external database together.

In the project, based on the function nodes provided in Dynamo, the specific visual programming mainly includes three kinds of modules (Fig. 4):

(i) "Host" elements generation based on coordinates (Green part in Fig. 4). Based on the parametric "Family", the instance, including floor, wall, roof, stair, column, etc., can be created in the right position based on the coordinates. That is, the original point and reference levels are initially defined. And the floor is located at the original point. As for the similar structure, the list function can be utilized.

(ii) "Host Based" elements generation based on the relative relationship with the "Host" elements (Blue part in Fig. 4). The door and window are created based on the relative position in the wall.

(iii) Parameter modification (Orange part in Fig. 4). The parameters can be modified in either the Revit interface or Dynamo nodes. The element parameter can be adjusted in Dynamo by indicating the parameter name and corresponding value. And arbitrary parameter modification window can be added by the users in the application.

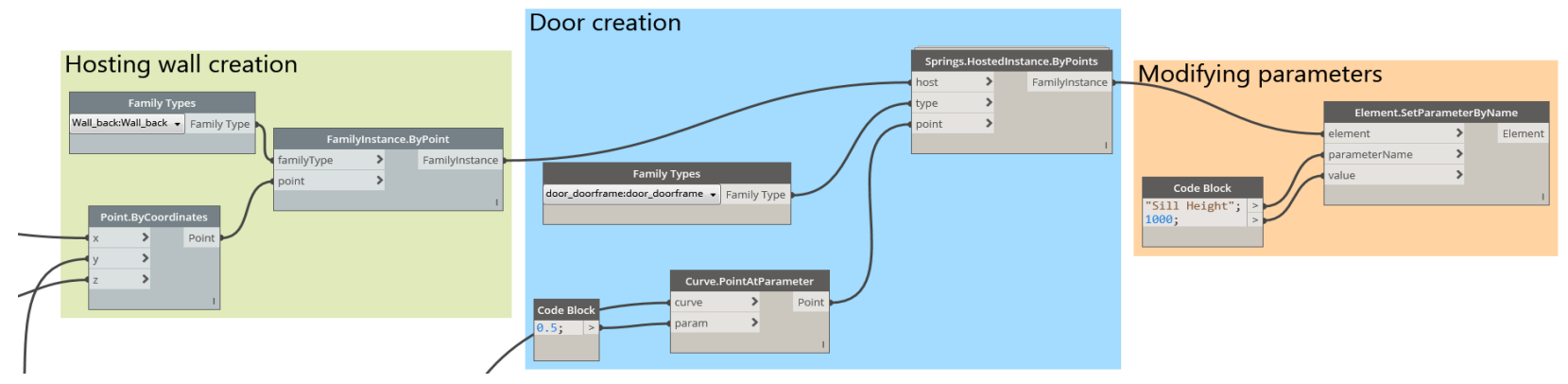

Fig. 4. Dynamo functions for the BIM modelling from primitives 


\section{RESULTS AND DISCUSSION}

\subsection{HBIM (LoD3)}

The obtained model is a geometric model with parameters and semantics. The parameters can be changed in Revit interface and Dynamo nodes. Fig. 5 and Fig. 6 shows the final model in 2D and $3 \mathrm{D}$ views. As for the geometric aspect, the obtained model is an architecturally detailed model with considerably complex shape about the object's parts.

The level of detail (LoD) concept, both defined in the fields of GIS and BIM, is in practice principally used to differentiate multi-scale representation of semantic 3D models and indicate the geometric detail of a model, primarily of buildings (Biljecki et al., 2016). The created model is accordant with most-used LoD3 in CityGML or LoD300 in IFC, which contains the full exterior of an architectural model with detailed wall and roof structures, doors and windows.

Compared with the most LoD3 models currently available which have been constructed by tedious and time-consuming manual works (Donkers et al., 2015), the choice of Dynamo visual programming maintains the need to reduce human involvement during the modelling process. The current work automates the semantic modelling from parametric "Family" elements aiming at lost historic buildings, while the creation of "Families" is still in a manual way.

As for the current modelling process and obtained model, two open issues are carried out. The first is the combination of ontology to present the semantics and reduce the human involvement in parametric family elements generation. The second is to apply the visual programming on as-built modelling process from solid geometry.
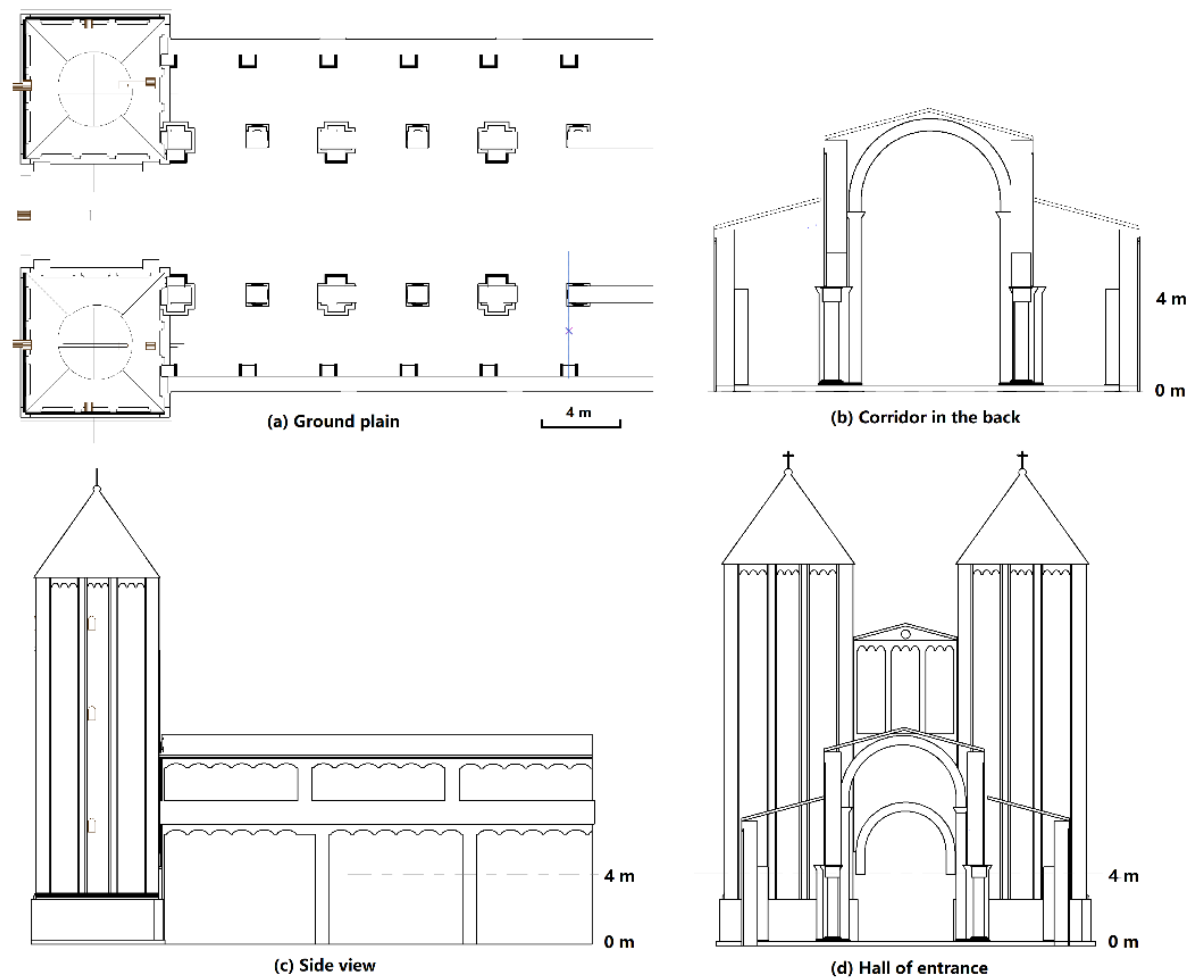

Fig. 5. The final BIM model in 2D views.

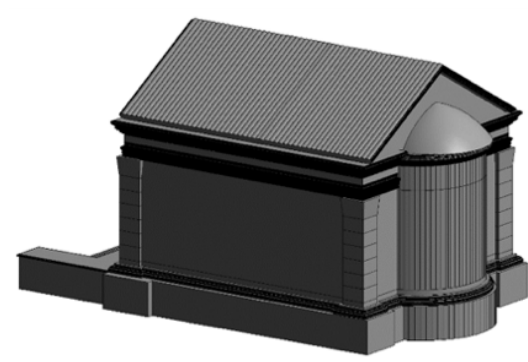

(a) The Petit château du Meisenbach

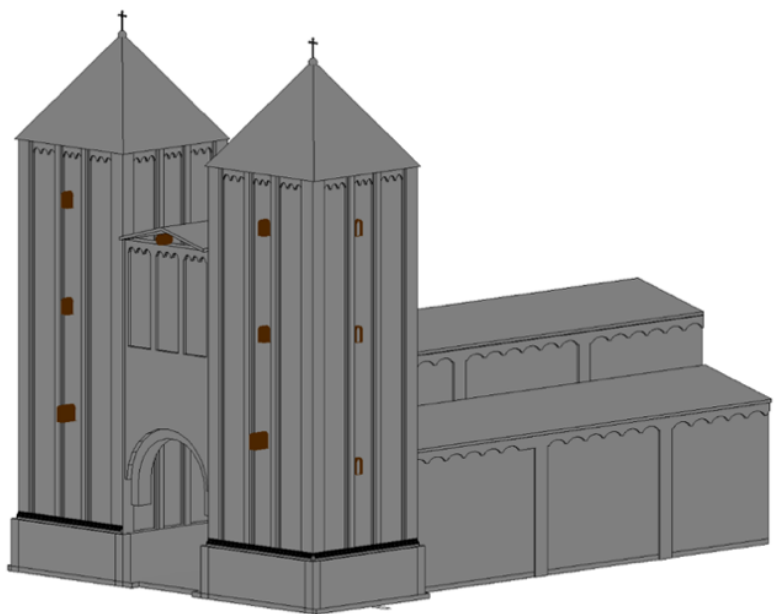

(b) The Abbey of Niedermunster

Fig. 6. The obtained 3D parametric model 


\subsection{Connection with ontology}

BIM approach includes information directly related to the object or its parts (both tangible and intangible such as material, dating, deterioration), yet it lacks a large amount of semantics about different context aspects (for example historical context, social information, environmental resources, other heritage artefacts information, etc.) (Simeone et al., 2015). In the field of built heritage, BIM model is integrated with ontology semantic relational system to enhance the representation of heritage knowledge and semantic reasoning. The integration can be an adhoc development based on BIM software (Acierno et al., 2017), and a two-step modelling process by migrating IFC files to ontology environment for semantics richness (Quattrini et al., 2017; Pauwels et al., 2017). The combined entity thus includes both object-oriented information, typically found in BIM platform, and semantic information, usually found in ontology modelling systems (Kalay et al., 2014).

Currently, the IfcOWL project converting EXPRESS/IFC schemas to ontology has embraced by building SMART as future development of the IFC standard (Pauwels et al., 2017). Shown as the green part of Fig.6, the obtained BIM model in standard Revit can be straightforwardly export to IFC data compliant with the EXPRESS schema. And then use the IFC-to-RDF conversion tool to get RDF (Resource Data Framework) data, including both BIM data and data enrichment (Quattrini et al., 2017). Once the data are represented in RDF, we can straightforwardly upgrade it to OWL format in Protégé and integrate the semantic information and other interested aspects information, which formalize the architectural knowledge rules.

Moreover, the current documentation-based modelling process consists of manual parametric elements creation and semiautomated model generation. The key problem is how to convert the formalized rules to the Dynamo and reduce the human involvement. Although most of current works are BIM-toontology modelling process, we expect to conduct the knowledge-based BIM modelling, shown as the red part in Fig. 7. The knowledge about the geometric shape and coordinates can be digitalized from paper recording to ontology formalized format, and there exists the possibility to support the simple geometric primitive generation and location definition.

In Fig. 7, the workflow in green presents the creation of ontology from documentation and BIM. The red dashed outline shows the expected knowledge-based BIM modelling with built ontology.

\subsection{As-built BIM process}

The Dynamo-based modelling begins from the manually created Revit Family to semi-automatically built BIM model, which can be introduced to as-built HBIM modelling as well. The scan-toHBIM process creates the BIM solid components on the reference of surface point clouds, which remains a time- consuming manual process and thus is expected to reduce the human involvement (Dore and Murphy, 2017).

The expected Dynamo-based HBIM modelling transfers the geometric structures to HBIM model via Revit Dynamo visual programming. The fundamental and manual work is to segment the raw point cloud into mesh solid geometry representing building components (i.e., walls, roofs, columns, slabs) (Remondino et al., 2012). Then, by visual programming in Dynamo environment, the solid geometry is transferred into Revit Family elements, and then the parametric relationships among building objects are also defined. That is, the utilization of Dynamo conducted the element-to-BIM process, which directly transferred the segmented solid geometry to BIM environment with reduced manual processing. The obtained BIM model, however, has limited parameters and lacks explicit geometric description because the automatic Revit parametric Family generation from geometry returns to non-editable solid elements.

\section{CONCLUSION}

This paper presented a methodology for the generation of unbuilt HBIM from segmented solid elements to reveal the lost constructions according to the archives and ruins. In the project, the modelling process consists of manual parametric "Family" creation and semi-automated building reconstruction. Starting from the collection of historical materials, related parametric "Family" classes are firstly created in HBIM environment. Then, the semantic model composed by the parametric elements is generated in an automated way by Dynamo visual programming package.

These results show the feasibility of utilization of Dynamo to reduce the human involvement in the process of BIM modelling from segmented solid elements. The LoD of the BIM model is based on the solid elements, in which the more parameters and higher accurate geometry is manually created, the higher LoD is obtained. However, the current workflow provides two aspects of potential improvement aiming at the HBIM related topics. The first lies in the input of measurement information in both family creation and Dynamo reconstruction process. The ongoing work focuses on the creation of ontology semantics and such knowledge-based BIM modelling. The second is employed the proposed outline to as-built HBIM modelling application.

\section{ACKNOWLEDGEMENT}

This research is supported by China Scholarship Council (Grant CSC No. 201504490008).

\section{REFERENCES}

Acierno, M., Cursi, S., Simeone, D., \& Fiorani, D. (2017). Architectural heritage knowledge modelling: An ontology-based framework for conservation process. Journal of Cultural Heritage, 24, 124-133.

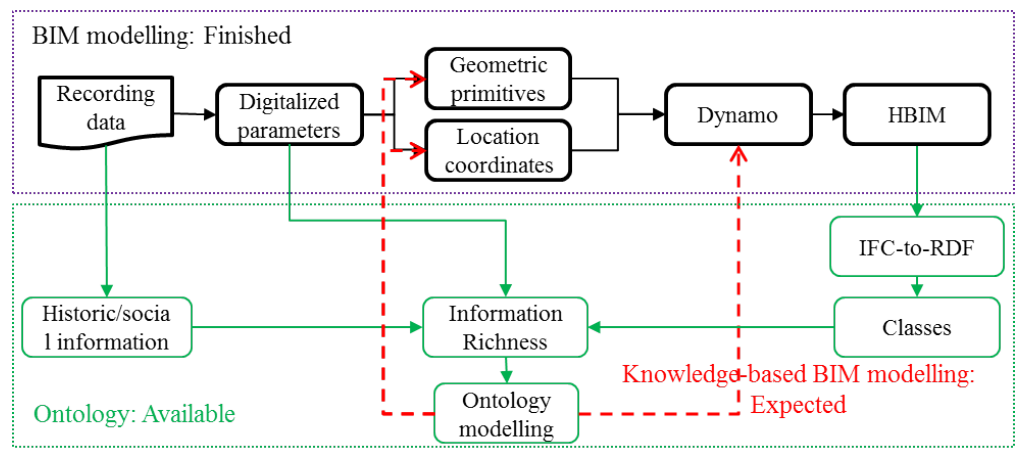

Fig. 7. The connection between BIM geometric aspect model and ontology semantics aspect model. 
Apollonio, F. I., Gaiani, M., \& Sun, Z. (2013). 3D Modeling and Data Enrichment in Digital Reconstruction of Architectural Heritage. XXIV International CIPA Symposium, XL-5/W2, 4348.

Asl, M. R., Zarrinmehr, S., Bergin, M., \& Yan, W. (2015). BPOpt: A framework for BIM-based performance optimization. Energy and Buildings, 108, 401-412.

Barazzetti, L., Banfi, F., Brumana, R., \& Previtali, M. (2015). Creation of parametric BIM objects from point clouds using NURBS. The Photogrammetric Record, 30(152), 339-362.

Biagini, C., Capone, P., Donato, V., \& Facchini, N. (2016). Towards the BIM implementation for historical building restoration sites. Automation in Construction, 71, 74-86.

Biljecki, F., Ledoux, H., \& Stoter, J. (2016). An improved LOD specification for 3D building models. Computers, Environment and Urban Systems, 59, 25-37.

Boeykens, S., Himpe, C., \& Martens, B. (2012). A Case Study of Using BIM in Historical Reconstruction. The Vinohrady Synagogue in Prague. Digital Physicality | Physical Digitality, 1, 729-738.

Casu, P., \& Pisu, C. (2016). BIM Application in Documenting and Recreating Lost Architectural Heritage. In IGI Global Handbook of Research on Visual Computing and Emerging Geometrical Design Tools, 144-173.

De Luca, L., Busayarat, C., Stefani, C., Véron, P., \& Florenzano, M. (2011). A semantic-based platform for the digital analysis of architectural heritage. Computers \& Graphics, 35(2), 227-241.

Diethrich, J. (2017). Modélisation tridimensionnelle du monument antique du Meisenbachschloessel de Sparsbach (BasRhin), Master thesis, INSA Strasbourg (in French).

Donkers, S., Ledoux, H., Zhao, J., \& Stoter, J. (2015). Automatic conversion of IFC datasets to geometrically and semantically correct CityGML LOD3 buildings. Transactions in GIS, 20(4):547-569.

Dore, C., \& Murphy, M. (2017). Current state of the art historic building information modelling. International Archives of the Photogrammetry, Remote Sensing \& Spatial Information Sciences, XLII-2/W5, 185-192.

Dylla, K., Frischer, B., Müller, P., Ulmer, A., \& Haegler, S. (2008). Rome reborn 2.0: A case study of virtual city reconstruction using procedural modeling techniques. Computer Graphics World, 16(6), 62-66.

Fai, S., \& Rafeiro, J. (2014). Establishing an Appropriate Level of Detail (LoD) for a Building Information Model (BIM)-West Block, Parliament Hill, Ottawa, Canada. ISPRS Annals of the Photogrammetry, Remote Sensing \& Spatial Information Sciences, 2 (5), 123-130.

Kalay, Y. E., Schaumann, D., Hong, S. W., \& Simeone, D. (2014) Beyond BIM: Next generation building information modeling to support form, function, and use of buildings. Building Information Modeling: BIM in Current and Future Practice, 321-335.

Koehl, M., \& Grussenmeyer, P. (2008). 3D model for historic reconstruction and archaeological knowledge dissemination: the Niedermunster Abbey's project (Alsace, France). International Archives of the Photogrammetry, Remote Sensing \& Spatial Information Sciences, XXXVII/B5, 325-330.

López, F. J., Lerones, P. M., Llamas, J., Gómez-García-Bermejo, J., \& Zalama, E. (2017). A framework for using point cloud data of Heritage buildings towards geometry modeling in a BIM context: a case study on Santa Maria la Real de Mave Church. International Journal of Architectural Heritage, 11 (7), 965-986.

Ludwig, M., Herbst, G., Rieke-Zapp, D., Rosenbauer, R., Rutishauser, S., \& Zellweger, A. (2013). The advantages of parametric modeling for the reconstruction of historic buildings. The example of the in war destroyed church of St. Catherine (Katharinenkirche) in Nuremberg. International Archives of the Photogrammetry, Remote Sensing \& Spatial Information Sciences, XL-5/W1, 161-165.

Macher, H., Landes, T., \& Grussenmeyer, P. (2017). From Point Clouds to Building Information Models: 3D Semi-Automatic Reconstruction of Indoors of Existing Buildings. Applied Sciences, 7(10), 1030.

Murphy, M., McGovern, E., \& Pavia, S. (2009). Historic building information modelling (HBIM). Structural Survey, 27(4), 311327.

Murphy, M., McGovern, E., \&Pavia, S. (2013). Historic Building Information Modelling-Adding intelligence to laser and image based surveys of European classical architecture. ISPRS Journal of photogrammetry and remote sensing, 76, 89-102.

Pauwels, P., Krijnen, T., Terkaj, W., \& Beetz, J. (2017). Enhancing the ifcOWL ontology with an alternative representation for geometric data. Automation in Construction, $80,77-94$.

Quattrini, R., \& Baleani, E. (2015). Theoretical background and historical analysis for 3D reconstruction model. Villa Thiene at Cicogna. Journal of Cultural Heritage, 16(1), 119-125.

Quattrini, R., Pierdicca, R., \& Morbidoni, C. (2017). Knowledgebased data enrichment for HBIM: Exploring high-quality models using the semantic-web. Journal of Cultural Heritage, 28, 129139.

Remondino, F., Lo Buglio, D., Nony, N., \& De Luca, L. (2012). Detailed primitive-based 3D modeling of architectural elements. International Archives of the Photogrammetry, Remote Sensing \& Spatial Information Sciences, XXXIX/B5, 285-290.

Simeone, D., Cursi, S., Toldo, I., \& Carrara, G. (2014). B(H)IMbuilt heritage information modelling-extending BIM approach to historical and archaeological heritage representation. In FusionProceedings of the 32nd eCAADe Conference, 1, 613-622.

Thomson, C., \& Boehm, J. (2015). Automatic geometry generation from point clouds for BIM. Remote Sensing, 7(9), 11753-11775.

Volk, R., Stengel, J., \& Schultmann, F. (2014). Building Information Modeling (BIM) for existing buildings-Literature review and future needs. Automation in construction, 38, 109127.

Xiong, X., Adan, A., Akinci, B., \& Huber, D. (2013). Automatic creation of semantically rich $3 \mathrm{D}$ building models from laser scanner data. Automation in Construction, 31, 325-337.

Yang, X., Koehl, M., \& Grussenmeyer, P. (2017). Parametric Modelling of as-built Beam Framed Structure in BIM Environment. International Archives of the Photogrammetry, Remote Sensing \& Spatial Information Sciences, XLII-2/W3, 651-657.

Yang, X., Koehl, M., Grussenmeyer, P., \& Macher, H. (2016). Complementarity of historic building information modelling and geographic information systems. International Archives of the Photogrammetry, Remote Sensing \& Spatial Information Sciences, XLI/B5, 437-443. 